\title{
Pesquisa e Desenvolvimento de Formulações para Proteção de Protoxinas de Bacillus e Outras Bactérias Esporuladas Entomopatogênicas
}

\section{Searching and Developing Formulations to Protect Bacillus Protoxins and Other Entomopathogenic Sporulated Bacteria}

DOI: $10.46919 / \operatorname{archv} 1 \mathrm{n} 5-017$

Recebimento dos originais: 10/07/2020

Aceitação para publicação: 30/08/2020

\section{Vera Cristina Pessoa de Lima}

Bióloga pela Universidade Celso Lisboa

Instituição: Laboratório de Fisiologia Bacteriana- LFB/Instituto Oswaldo Cruz- FIOCRUZ

Endereço: Av. Brasil no 4360, CEP: 21040-900 salas: 300;308;310;312 Manguinhos, Rio de Janeiro, Brasil)

E-mail: vera@ioc.fiocruz.br

\section{Adriana Marcos Vivoni}

Doutora em Ciências pela Universidade Federal do Rio de Janeiro- UFRJ

Instituição: Laboratório de Fisiologia Bacteriana- LFB/Instituto Oswaldo Cruz- FIOCRUZ

Endereço: Av. Brasil no 4360, CEP: 21040-900 salas: 300;308;310;312 Manguinhos, Rio de Janeiro, Brasil)

E-mail: avivoni@ioc.fiocruz.br

\section{Leon Rabinovitch}

Doutor em Enzimologia e Tecnologia das Fermentações pela Universidade Federal Fluminense - UFF Instituição: Laboratório de Fisiologia Bacteriana- LFB/Instituto Oswaldo Cruz- FIOCRUZ

Endereço: Av. Brasil no 4360, CEP: 21040-900 salas: 300;308;310;312 Manguinhos, Rio de Janeiro, Brasil)

E-mail: leon@ioc.fiocruz.br

\section{Maria Alice Varjal de Melo Santos}

Doutora em Saúde Pública pelo Centro de Pesquisa Aggeu Magalhães-CPqAM

Instituição: Centro de Pesquisa Aggeu Magalhães-CPqAM/Fiocruz

Endereço: Av. Professor Moraes Rego s/n, CEP: 50.740-465 Campus da UFPE, Recife/PE - Brasil.

E-mail: mavarjal@cpqam.fiocruz.br

\section{Ricardo Tadeu Lopes}

Doutor em Engenharia Nuclear pela Universidade Federal do Rio de Janeiro- UFRJ Instituição: Programa de Engenharia Nuclear - COPPE-UFRJ

Endereço: Av. Pedro Calmon 550- Cep: 21941972 - Cidade Universitária UFRJ, Rio de Janeiro, Brasil.

E-mail: rlopes@coppe.ufrj.br 


\title{
RESUMO
}

Bacillus e Gêneros correlatos apresentam espécies que são larvicidas, de mosquitos vetores de doenças tropicais. Alguns sorovares produzem protoxinas as quais os insetos sensíveis transformam em estruturas químicas altamente tóxicas para si. Com base nesse conhecimento, alguns sorovares de Bacillus thuringiensis e de Lysinibacillus sphaericus são usados em preparações inseticidas larvicidas. Na maioria desses inseticidas os esporos bacterianos estão presentes juntamente com as tóxinas, por serem inócuos aos homens e à maioria dos animais, bem como são apresentados em diferentes formulações contendo ácidos orgânicos, espessantes, conservantes, emulsionantes, desintegradores e água. No entanto, alguns usuários de produtos comerciais preferem larvicidas bacterianos isentos de esporos viáveis, para aplicação ambiental em larga escala. Este trabalho elaborado com formulação especial e experimentado com esporos viáveis de L. sphaericus 2362, ativos contra Culex quinquefasciatus e Anopheles darlingi, cultivado em NYSM gerador de biomassa altamente esporogênica e tóxigênica evidencia que, para a formulação empregada, o desenvolvimento de um concentrado emulsionável, os esporos presentes tratados com Co-60 (4.86h-1;fator 1.13) podem tender para 0 com aplicação de $20 \mathrm{kGy}$ independente da conservação de alta atividade larvicida preservada contra $C$. quinquefasciatus. Alguns parâmetros importantes do processo de fermentação, de atividade e dosagem biológica serão mostrados neste trabalho.

Palavras-Chaves: Sorovares de Bacillus, esporos e Co-60

\begin{abstract}
Bacillus and related genera present larvicides species to mosquitoes that are vectors of tropical diseases. Some serovars produce protoxins which sensitive insects transform into chemical structures highly toxic to themselves. Based on this knowledge, some Bacillus thuringiensis and Lysinibacillus sphaericus serovars are used in larvicidal insecticidal preparations. In most of these insecticides, bacterial spores are present together with toxins, as they are harmless to men and most animals, as well as being presented in different formulations containing organic acids, thickeners, preservatives, emulsifiers, disintegrators and water. However, some users of commercial products prefer viable spore-free bacterial larvicides for largescale environmental application. In the present work elaborated with a special formulation that was assayed against viable spores of $L$. sphaericus 2362, active against Culex quinquefasciatus and Anopheles darlingi, cultivated in NYSM highly sporogenic and toxic biomass generator shows that, the formulation employed and development of an emulsifiable concentrate, the viable spores treated with Co-60 (4.86h-1; factor 1.13) may tend to 0 with application of $20 \mathrm{kGy}$ regardless of the conservation of high larvicidal activity preserved against $C$. quinquefasciatus. Some important parameters of the fermentation process that generate biomass toxic activity against mosquito larvae was achieved and shown in this work.
\end{abstract}

Keywords: Bacillus serovars, Spores and Co-60.

\section{INTRODUÇÃO}

Bacillus e Gêneros correlatos apresentam espécies que são larvicidas, particularmente de mosquitos vetores de doenças. Alguns sorovares produzem protoxinas as quais os insetos transformam em estruturas químicas altamente tóxicas para si próprios. Com base nesse conhecimento e achado, alguns sorovares de Bacillus thuringiensis e de Lysinibacillus sphaericus (ex B. sphaericus) são usados em preparações inseticidas. 
A utilização desses inseticidas tem- se mostrado seguro para o meio ambiente quando comparado com os inseticidas larvicidas convencionais. O desenvolvimento de um concentrado emulsionável de $L$. sphaericus, mostrou que testes realizados com a utilização de Co-60 em diferentes doses (kgy), os esporos presentes são inativados sem prejudicar as toxinas ativas. Tenta-se estabelecer o melhor valor de kgy para esta formulação.

\section{OBJETIVO}

Desenvolver preparações à base de L. sphaericus altamente entomotóxico;

Obter a toxina ativa e isenta de esporos viáveis;

Utilizar radiação ionizante para se alcançar a inativação exclusiva dos esporos.

\section{METODOLOGIA}

A cepa de L. sphaericus 2362 foi semeada em Ágar Nutriente com Metais e incubada a $33^{\circ} \mathrm{C}$ até $80 \%$ de esporulação. Em seguida, o induto bacteriano foi transferido para Erleymeyer contendo $35 \mathrm{~mL}$ de $\mathrm{NaCl}$ a $0,85 \%$ onde ficou sob agitação por $2 \mathrm{~h}$. Desta suspensão, colocou-se $6 \mathrm{~mL}$ em 5 tubos para a realização da Termorresistência a $70^{\circ} \mathrm{C}$ por $15 \mathrm{~min}$. As diluições foram realizadas na proporção de 1:10 e delas plaqueadas $100 \mu \mathrm{L}$ em placas de Petri contendo Ágar Plate Count (PCA). Da suspensão-mãe, tomou-se $50 \mu \mathrm{L}$ do inóculo e transferiu-se para 4 Erleymeyer contendo $100 \mathrm{~mL}$ de Caldo NYSM, onde ficou sob agitação a $33^{\circ} \mathrm{C}$ até $80 \%$ de esporulação. Transferiu-se a suspensão para 6 tubos Falcon e centrifugou-se até "pellet" firme, que foi lavado com $1 \mathrm{~mL}$ de água destilada e re-centrifugado. Suspendeu-se o "pellet" em $5 \mathrm{~mL}$ de salina e destribuiu-se em 12 Eppendorf com $500 \mu \mathrm{L}$ cada, e novamente centrifugou-se. Este processo se repetiu várias vezes quando se separou 6 Eppendorf para receberem respectivamente as doses em kgy $(5,0 ; 7,5 ; 10 ; 12,5 ; 15 ; 17,5$ e 20) com Co-60.

\section{RESULTADOS}

Após a irradiação ficou demonstrado que a dose de $20 \mathrm{kgy}$ apresentou melhor resultado quanto à inativação de esporo com a preservação da toxina. As amostras foram separadas em frascos estéreis em biomassa irradiada e não irradiada, onde foram secas, pesadas e enviadas ao CPqAM-PE para a determinação de potência UTI. Para o ensaio qualitativo do tipo "mata não mata" utilizou-se larvas L3 jovens de Culex quinquefasciatus. O mesmo processo foi feito para a biomassa não irradiada. Os resultados mostraram que as preparações com Larvas tiveram 100\% de mortalidade, como era esperado. 


\section{CONCLUSÃO}

O sistema empregado permitiu separar toxicidade de esporos viáveis.

\section{REFERÊNCIAS}

1- Rabinovitch, Leon; VIVONI, ADRIANA MARCOS ; Machado, Vilmar ; Knaak, Neiva ; Berlitz, Diouneia Lisiane ; Polanczyk, Ricardo Antonio ; FIUZA, Lidia Mariana . Bacillus thuringiensis Characterization: Morphology, Physiology, Biochemistry, Pathotype, Cellular, and Molecular Aspects. Bacillus thuringiensis and Lysinibacillus sphaericus. 1ed.: Springer International Publishing, 2017, v. , p. $1-18$.

2- Rabinovitch, Leon; DEL MASTRO, NÉlIDA L.; SILVA, CLÁUDIA M.B. ; SANTOS, BERNADETE S. ; RESENDE, MARCELO C. ; VIVONI, ADRIANA MARCOS ; ALVES, REGINA S.A. . Inativação seletiva de esporos mantendo atividade larvicida em Bt sorovar israelensis irradiada com raios gama. Neotropical Biology and Conservation, v. 9, p. 120-124, 2014.

3- RABINOVITCH, L.; COUTINHO, C. J. P. A. ; SILVA, C. M. B. E. ; ALVES, R. S. A. ; ALVES, Luis F.A. ; CAVADOS, Clara de Fátima Gomes . Bioprodutos à base de Bacillus entomopatogênicos em programas de controle de vetores na América Latina. In: Sérgio Batista Alves; Rogério Biaggioni Lopes. (Org.). Controle Microbiano de Pragas na América Latina - Avanços e Desafios. 1ªed.Piracicaba: Fundação de Estudos Agrários Luiz de Queiroz - FEALQ, 2008, v. 14, p. 137-170.

4- CARVALHO, L. R. ; ATAIDE, Livia Maria Silva ; SILVA, Cleider Rodrigues ; SANTOS, B. DE S. ; AZEVEDO, Vasco Ariston de Carvalho ; RESENDE, Marcelo Carvalho de ; RABINOVITCH, L. . Comparison between highly toxic Bacillus thuringiensis serovar israelensis and Bacillus sphaericus strains against Lutzomyia longipalpis LUTZ \& NEIVA 1912 (Diptera, Psychodidae, Phlebotominae) larvae. Neotropical Biology And Conservation, v. 2, p. 80-83, 2007

5- CAVADOS, Clara de Fátima Gomes; FONSECA, Rodrigo N ; CHAVES, Jeane Quintanilha ; COUTINHO, Carlos José Pc Araujo ; RABINOVITCH, L. . A new black fly isolate of Bacillus thuringiensis autoagglutinating strain highly toxic to Simulium pertinax (Kollar) Diptera, Simuliidae) larvae. Memórias do Instituto Oswaldo Cruz, Rio de Janeiro, v. 100, n.7, p. 795-797, 2005.

6- RABINOVITCH, L.; SILVA, C. M. B. E. ; ALVES, R. S. A. . Controle biológico de vetores de doenças tropicais utilizando Bacillus entomopatogênicos. In: Itamar Soares de Mello; João Lúcio de Azevedo. (Org.). Controle Biológico. 1ªed.Brasília: EMBRAPA Meio Ambiente, 2000, v. 2, p. 17-85

7- SILVA, K. R. A. ; RABINOVITCH, L. ; SELDIN, L. . Phenotypic and genetic diversity among Bacillus sphaericus strains isolated in Brazil, potencially useful as biological agents against mosquito larvae. Research in Microbiology (Paris) ${ }^{\text {JCR }}$, Paris, v. 150, p. 153-160, 1999.

8- RABINOVITCH, L.. Situação atual e necessidade de pesquisa de controle biológico de vetores d e importância para a Saúde Pública. Biotecnologia Ciência \& Desenvolvimento, Rio de Janeiro, v. 1, p. 42 45, 1997. 
9- CONSOLI, R. A. ; SANTOS, Bernadete de Souza; LAMOUNIER, M. A. ; SECUNDINO, N. F. ; RABINOVITCH, L. ; SILVA, C. M. B. E. ; ALVES, R. S. A. ; CARNEIRO, N. F. F. . Efficacy of a new formulation of Bacillus sphaericus 2362 against Culex quinquefasciatus (Diptera: Culicidae) in Montes Claros, Minas Gerais, Brazil. Memórias do Instituto Oswaldo Cruz (Online) ${ }^{\mathrm{JCR}}$, v. 92, p. 571-573, 1997

10- CONSOLI, R. A. ; PINTO, C. J. ; OLIVEIRA, M. A. ; SANTOS, Bernadete de Souza ; LAMOUNIER, M. A. ; ALVES, R. S. A. ; SILVA, C. M. B. E. ; RABINOVITCH, L. . Some environmental and biological factors influencing the activity of entomopathogenic Bacillus on mosquito larvae in Brazil. Memórias do Instituto Oswaldo Cruz ${ }^{\text {JCR }}$, Rio de Janeiro, v. 90, n.1, p. 121-124, 1995 